\title{
A constituição da atenção voluntária no interior do processo de periodização do desenvolvimento humano
}

\author{
The constitution of voluntary attention in the human development \\ periodization process
}

\author{
Hilusca Alves Leite ${ }^{1}$ \\ Marcelo Ubiali Ferracioli ${ }^{2}$
}

\begin{abstract}
Resumo:
Neste artigo discutimos a constituição da atenção e sua relação com o pensamento no interior da periodização do desenvolvimento humano a partir do aporte teórico da Psicologia Histórico-Cultural. Trata-se de estudo teórico-bibliográfico cujo objetivo foi expor as interdependências entre atenção e pensamento, localizando no processo de formação de conceitos a inversão que ocorre na relação entre estas funções dentro da periodização do desenvolvimento, discutindo a atividade-guia de cada período e as características da atenção nestas atividades. Por fim, demonstradas as referidas intervinculações, defendemos que a neoformação das atividades-guia e seus motivos podem e devem se articular a iniciativas intencionais de desenvolvimento da atenção, bem como do autocontrole da conduta de crianças e adolescentes tendo em vista o pleno desenvolvimento do comportamento organizado.
\end{abstract}

Palavras-chave: Atenção. Pensamento. Desenvolvimento. Atividade. Periodização.

\begin{abstract}
In this article we discuss the constitution of the attention and its relation with the process of thinking in the periodization of human development based on the theoretical contribution of the Historical-Cultural Psychology. It consists in a theoreticalbibliographic study whose objective is to present the correlation between attention and thinking, situating throughout the process of concept formation the inversion that occurs in the relation between these functions within the periodization of development, discussing the guiding activity of each period and the characteristics of attention in these activities. Lastly, after pointing the referred interlinkages, we endorse the fact that neoformation of guiding activities and their motives can and should be linked to intentional initiatives to develop attention, as well as the self-control of children and adolescents' conduct, considering the full development of organized behavior.
\end{abstract}

Keywords: Attention. Thinking. Development. Activity. Periodization.

\footnotetext{
${ }^{1}$ Docente na Universidade Estadual de Maringá-PR. E-mail: hilusca.leite@yahoo.com.br

2 Docente na Universidade Estadual de Ponta Grossa-PR. Líder do Grupo de Pesquisa em Psicologia Concreta (GEPCO). E-mail: ferracioli19@gmail.com
} 


\section{Introdução}

Seguindo a proposta deste dossiê de abordar aspectos relevantes do desenvolvimento humano a partir do aporte teórico da Psicologia HistóricoCultural, discutiremos a constituição da atenção no interior desse processo. Para tal, incialmente faremos uma breve conceituação desta função psíquica para em seguida apresentarmos as transformações que ocorrem nela ao longo do desenvolvimento ontogenético na medida em que se transformam as atividades que orientam a ação do sujeito no mundo. É importante destacar que abordamos especificamente a função psíquica atenção por questões de demarcações textuais, no entanto, não consideramos de forma alguma que a constituição da atenção possa se dar em separado das demais funções.

Dentre as funções psíquicas que participam do comportamento humano organizado, a atenção é considerada a base sobre a qual se organizam a direcionabilidade e a seletividade dos processos mentais. Nenhuma atividade humana poderia ser realizada caso não existisse a seletividade promovida pela atenção, pois a quantidade de informações recebida seria demasiadamente grande e confusa. Assim, a atenção é a responsável por demarcar os elementos essenciais para a atividade mental, vinculando-se a seu funcionamento organizado (LURIA, 1979).

A atenção, portanto, é uma das formas pelas quais a percepção se torna consciente, visto que ela compreende a "seleção de certos estímulos, a inibição de estímulos concorrentes e a retenção da imagem selecionada na consciência" (MARTINS, 2013, p. 143). Dessa forma, eleva o nível da atividade sensorial, cognitiva e motora - isto é, ao participar de outras funções como o pensamento, a memória, a imaginação, os afetos e outras - abre a possibilidade para o comportamento orientado para fins específicos.

De acordo com Martins (2013, p. 143), graças a esta seletividade se forma uma imagem focal daquilo que é captado o que permite que organizemos nosso comportamento em relação ao que é abarcado na imagem focal. "A eleição da figura sobre o fundo corresponde à instituição do foco da atenção. Essa dinâmica evidencia, portanto, o alto grau de condicionabilidade entre atenção e percepção".

Tais capacidades promovidas pela atenção advém de um processo de desenvolvimento que pode ser considerado um traço imanente ao 
desenvolvimento cultural da humanidade. Ou seja, a vida em sociedade exigiu dos indivíduos reações cada vez mais dirigidas e voluntárias, tornando-as indispensáveis à construção da cultura e, consequentemente, do próprio ser humano. É, portanto, como causa e efeito do trabalho, na condição de ato fundante do ser social, que a capacidade atentiva se engendra ao longo do desenvolvimento da espécie humana.

No plano ontogenético, a atenção deve ser entendida como um produto do desenvolvimento cultural da criança, pois para a teoria em questão, tudo aquilo que diz respeito ao comportamento organizado só é possível porque o sujeito participa de uma dada sociedade, em uma dada cultura, com uma dada organização e é o movimento de internalização dos instrumentos físicos e simbólicos produzidos socialmente que provoca as transformações no desenvolvimento psíquico. Nas palavras de Vigotski:

[...] seu desenvolvimento (da atenção) começa com o primeiro gesto indicativo, por meio do qual os adultos buscam dirigir a atenção da criança e com o primeiro gesto independente da criança, com o qual começa a dirigir a atenção de outros. Mais tarde, em forma muito mais desenvolvida, a criança domina já todo sistema dos meios para dirigir a atenção dos demais. Esse sistema de meios é a linguagem atribuída de sentido; passado algum tempo, a criança aplica a si as mesmas normas de conduta que outros lhe aplicaram e que ela utiliza em suas relações com os demais. Deste modo começa a dirigir sua própria atenção, transportando sua atenção ao plano voluntário (Vygotski, 1996, p. 143, tradução e parêntese nosso).

Do exposto é possível depreender que, ao abordar o desenvolvimento da atenção, Vygotski (1995) está considerando duas linhas de desenvolvimento para esta função. O desenvolvimento natural e o cultural. Considera, portanto, que nossa atenção não se apresenta da mesma forma ao longo do desenvolvimento. Ao nascer a criança conta com uma forma de atenção que reage de modo reflexa aos estímulos mais fortes, extinguindo-se assim que o estímulo cessar, que outro estímulo mais forte entrar em concorrência ou quando o estímulo deixar de ser novidade.

A atenção na sua forma natural ou involuntária é, portanto, conforme Smirnov e Gonobolin (1960), um reflexo de orientação motivado por mudanças e oscilações do meio externo. A aparição de um novo estímulo provoca a atenção 
involuntária. O aparato receptor se adapta para captar melhor o novo estímulo (olhar, ouvir, cheirar) e reagir a ele da melhor forma possível. Esta é, portanto, determinada pelo estado do sujeito, tem importância as necessidades da pessoa e a ação que tem em relação a isto. "Tudo o que está relacionado com a satisfação ou insatisfação das necessidades; tudo o que corresponde aos interesses dirigidos a atitude emocional claramente manifesta e determinada, se faz facilmente objeto da atenção involuntária” (SMIRNOV; GONOBOLIN, 1960, p. 181).

Smirnov e Gonobolin (1960) explicam que a novidade também é importante para despertar a atenção involuntária, porém, esta cumpre tal função apenas na medida em que pode ser compreendida ou incita a pensar sobre ela. Para que isto ocorra, deve estar relacionada com a experiência anterior do sujeito; do contrário, a novidade chamará a atenção por pouco tempo. Podemos pensar como exemplo, no impacto que uma música tem ao ser apresentada para um bebê no seu primeiro ano de vida e para uma criança um ou dois anos mais velha. No primeiro caso, a música despertará a atenção do bebê especialmente se for uma música apresentada pela primeira vez, no entanto, será necessário que o adulto cante pare ele, faça gestos que acompanhem a música para que este se mantenha atento por mais tempo, uma vez que o bebê não dispõe ainda do recurso da linguagem para acompanhar a música. Já com a criança mais velha, embora os gestos do adulto e o cantar junto ainda sejam necessários (e importantes), podemos pensar que, terá mais condições de manter-se atento e até mesmo de realizar tentativas de acompanhar a canção já que dispõe de certo repertório de palavras. Sobre isso, os autores supracitados expõem que, para que a atenção elementar seja prolongada são indispensáveis reações condicionadas de orientação que só são possíveis quando, junto ao que é percebido, já existam conexões que permitam relacioná-lo com algo conhecido, caso contrário a duração do foco será pequena.

Em termos fisiológicos, Smirnov e Gonobolin (1960) explicam que atentar para algo ou alguma coisa, significa a existência da concentração de excitação em determinadas zonas do córtex cerebral; onde ocorre simultaneamente um foco de excitabilidade ótima e a inibição das demais zonas corticais. Sempre existe no córtex cerebral um foco de excitabilidade ótima, isso significa que a cada momento o sujeito está atento a alguma coisa. O foco de excitabilidade ótima 
assegura que o que está atuando sobre o cérebro tenha boa reflexão no aparelho psíquico. Isto determina, como já dito, o importante papel da atenção nas funções perceptivas. Funções estas que são premissas fundamentais para qualquer atividade.

A dinâmica desta relação entre a atenção e as demais funções psíquicas muda ao longo do desenvolvimento, o que possibilita que ela se torne voluntariamente organizada conforme se constitui o processo de pensamento do sujeito. Martins (2013) explica que o grau de desenvolvimento entre conexões internas que orientam a atenção e estímulos externos está condicionado ao desenvolvimento do pensamento em conceitos e em decorrência disto a atenção alcança seu estágio superior. Dessa forma, se nos estágios iniciais do desenvolvimento a atenção conduz à formação dos conceitos, pois está orientada externamente e é responsável pela imagem focal indispensável para que tal formação ocorra, com o desenvolvimento da atenção arbitrária, essa relação se inverte e, nela os conceitos adquirem a capacidade de dirigi-la.

De forma sucinta podemos esboçar algumas fases da constituição da atenção tomando como base proposição sintética de Martins (2013). Inicialmente a atenção imediata, natural, se transforma, por apropriação de signos externos, em atenção mediada; a atenção mediada se requalifica pela conversão dos signos externos em signos internos, isto é, pela sua superação em operações internas; e se converte novamente em atenção "imediata", porém não mais orientada pelo campo exógeno, mas diretamente determinada pelo motivo da atividade, sob condições nas quais o próprio sujeito domina a criação de estímulos aptos a dirigirem suas ações, o que coloca de vez a atenção a serviço de suas finalidades conscientes.

Para que tal movimento ocorra, não se pode perder de vista que o desenvolvimento psíquico só se dá na e pela atividade do sujeito (LEONTIEV, 2004), sendo que esta deve estar orientada por motivos e finalidades empreendidas conscientemente. Portanto, o desenvolvimento da atenção não se dá como algo em si mesmo, mas a partir das atividades que o sujeito realiza em diferentes momentos do seu desenvolvimento e do "lugar que a atenção passa a ocupar em relação ao pensamento, à memória, aos afetos etc., ou seja, das inter- 
relações e interdependências funcionais requeridas pela atividade cultural" (MARTINS, 2013, p. 154).

Em um primeiro momento é o adulto que organiza a atividade da criança e engendra nela a necessidade de permanecer na atividade. Cada momento do desenvolvimento conta com atividades centrais para que ocorra, isto é, são aquelas capazes de provocar saltos qualitativos reorganizando a personalidade da criança e a forma como esta se relaciona com o meio (LEONTIEV, 2004). Logo, é possível pensar em alguns aspectos a serem considerados nesta organização para que de fato haja tais mudanças qualitativas no psiquismo, incluindo aí a capacidade do sujeito em manter-se atento.

Dessa forma, pretendemos ao longo deste texto problematizar a existência da correlação entre a periodização do desenvolvimento psíquico e o desenvolvimento da atenção voluntária, evidenciando a atenção como um processo que se inverte na relação entre atenção e pensamento. Como antes expresso, num primeiro momento os processos de pensamento estão para a atenção, pois ocorrem na medida em que o sujeito percebe e atenta para algo; porém, conforme se dá o desenvolvimento e no interior deste processo há a internalização de signos que ampliam o domínio conceitual do sujeito, o pensamento gradualmente figura em primeiro plano e a atenção passa a estar a serviço dele.

Entendemos que abordar a constituição da atenção por este prisma nos possibilita a crítica à naturalização da atenção como função voluntária, bem como, abre possibilidades de fundamentar a orientação sistemática de atividadesguia pensando no desenvolvimento desta função.

Assim sendo, ao longo do texto procuramos expor as interdependências entre atenção e pensamento, localizando esse processo de inversão dentro da periodização do desenvolvimento, discutindo a atividade-guia de cada período e as características da atenção dentro destas atividades.

\section{O desenvolvimento em movimento: principais estágios do desenvolvimento e a constituição da atenção arbitrária}

Com o nascimento a criança experimenta um breve período de transição entre a vida intra e extrauterina. Nesse primeiro momento do desenvolvimento 
da criança o mundo apresenta-se ao bebê ainda de forma muito difusa e esta experimenta inicialmente um conjunto de sensações, denominados por Vygotski (2012) de estados emocionais, que podem ser agradáveis ou desagradáveis, como a fome e a saciedade por exemplo; porém o bebê não sabe identificar do que se trata. Tais estados se manifestam por meio da expressão do seu rosto, da entonação do seu choro, etc. Ao exercer os cuidados com a criança, o adulto procura reconhecer tais estados emocionais atendendo às suas necessidades e, ao fazê-lo, possibilita que seus processos perceptivos se expandam para além do reconhecimento deste conjunto de sensações agradáveis e/ou desagradáveis (estados emocionais) para percepções externas, passando aos poucos a reconhecer a voz das figuras mais próximas, traços das faces, cheiros, sons etc.

O ponto de partida para o desenvolvimento posterior da consciência é, pois, este emaranhado de sensações e percepções que aos poucos tomam forma e configuram um fundo sobre o qual se destaca para a criança um fenômeno mais ou menos limitado e estrutural, que ela percebe como uma qualidade especial neste fundo.

Em termos de processos atencionais, observamos aqui o que Vigotski e Luria (1996) denominam de atenção instintivo-reflexiva, uma expressão mais simples da atenção que pode ser reconhecida já nas primeiras semanas de vida, provocada por alguns estímulos suficientemente fortes. "Esse tipo de atenção caracteriza-se por seu caráter não intencional, não-volitivo, qualquer estímulo forte e repentino atrai imediatamente a atenção da criança e reconstrói seu comportamento" (VIGOTSKI; LURIA, 1996, p. 195).

O destaque gradual entre figura e fundo se dá com a intensa participação do adulto como ele mesmo uma figura que, ao exercitar os cuidados em relação à criança, apresenta-lhe o mundo dos objetos como outras figuras, possibilitando que seus processos atencionais se destaquem na medida em que coloca algumas coisas em evidência e, ao fazê-lo, relaciona-se em comunicação direta com a criança. Como consequência para a atividade psíquica e conduta social desta, esta comunicação com o outro, o cuidador, permite ao bebê "tomar consciência" de que alguém cuida dela e, diante disso, reagir de forma diferente a essa pessoa (VYGOTSKI, 2012). 
Desta forma, o primeiro contato do bebê com a realidade desde o início, inclusive quando cumpre as funções biológicas mais elementares, está socialmente mediado. Qualquer relação da criança com o mundo e a conformação psíquica que se organizará a partir daí, passa pelo adulto e concretiza-se com a ajuda de outra pessoa (SILVA, 2013).

Destacamos que o adulto é inicialmente o conteúdo central da atividade da criança, pois atua em comunidade psicológica com ele. O bebê passa primeiramente a dirigir-se aos objetos na presença do adulto como se esse fizessem parte de si, para, ao longo de seu desenvolvimento, diferenciar-se e atuar diretamente com os objetos. Por essa razão a presença do adulto no campo de visão do bebê é fundamental para que ele se sinta atraído pelos objetos expostos e com eles opere (CHEROGLU; MAGALHÃES, 2016).

É, portanto, em virtude desta relação com a figura do adulto, que ainda nos primeiros meses de vida são desenvolvidas no bebê as propriedades psicofísicas necessárias para que este se engaje na primeira atividade guia do seu desenvolvimento, a comunicação emocional direta. Tais propriedades, de acordo com Cheroglu e Magalhães (2016), são a diferenciação psíquica eu/não eu, o reflexo de orientação (intimamente vinculado à atenção instintivo-reflexiva antes explicada) e a reorganização motora.

Silva (2013) explica que a situação social na qual o recém-nascido se encontra possibilita que se engendre nele a necessidade de se comunicar com o adulto que o cuida. Trata-se de uma necessidade social que se desdobra dessa relação que o adulto estabelece com a criança ao exercer cuidados com ela e apresentar-lhe o mundo dos objetos. Tal necessidade constitui, de acordo com a autora, a base e a força motriz de todo o desenvolvimento psíquico ulterior da criança.

Cheroglu e Magalhães (2016) observam que as ações conjuntas bebêadulto-objetos sociais ampliam o rol de possibilidades de operações do bebê com o mundo dos objetos. Assim, de forma compartilhada, o adulto promove a possibilidade rudimentar da criança de dirigir seus próprios movimentos, complexificando os processos sensoriais, perceptuais e motores do bebê, necessários à formação paulatina da percepção tridimensional dos objetos, requalificando também o direcionamento da atenção dada a estes. As autoras 
destacam que a princípio os movimentos do bebê são pouco coordenados, porém, os processos sensoriais e de percepção são passíveis de serem dirigidos por meio da orientação da sua atenção pelo adulto. Elkonin (2009) exemplifica tal processo com situações em que o adulto suscita a concentração da criança em determinado objeto ao colocá-lo a uma distância na qual ela possa alcançar com as mãos, para em seguida afastá-lo um pouco, obrigando-a a estirar-se na direção do objeto, portanto movimentando-se de modo mais controlado.

Ao realizar tais ações, conforme mencionamos, o adulto está em comunicação com o bebê, promovendo nos processos atencionais uma estimulação de duplo gênero. Por um lado há a apresentação dos objetos e por outro a denominação destes. A fala do outro age como "estimulação catalizadora" ou como "sonoridade indicativa", ainda não associada a signos/significados propriamente ditos (MARTINS, 2013). Os "estímulos de gênero duplo", “[...] De um lado, são as propriedades intrínsecas aos objetos e fenômenos que atraem sua atenção, de outro, são as palavras que a dirigem. Assim, desde sua origem a atenção está orientada pelos objetos e pelo outro falante" (p. 152).

Embora a atenção orientada por estimulação de duplo gênero represente um avanço em relação à atenção instintivo-reflexiva e seja possível observar a ocorrência desta forma de atenção já no primeiro ano de vida, Martins (2013) destaca que este processo ocorre apenas em condições simples, quando não existem outros fatores distrativos no campo perceptual.

Destacamos aqui, nesse primeiro ano de vida, a importância do adulto como figura que engendra na criança a necessidade de comunicação e de reorganização dos processos perceptuais e motores. Daí a relevância da constante comunicação - marcada não apenas pela fala, mas também por gestos, entonações, contato visual - concomitantemente à apresentação dos objetos, situações, pessoas, como forma de orientar a atenção da criança e ampliar o desenvolvimento daquilo que abarca a imagem focal que vai configurando-se no psiquismo infantil.

Devido ao desenvolvimento motor que acontece ao longo do primeiro ano de vida, sobretudo à aquisição da marcha ereta, a criança alcança mais autonomia para explorar o ambiente; e as ações com os objetos passam a ocupar lugar de destaque na atividade desta, tornando seu comportamento cada vez 
mais instrumentalizado. Neste momento do desenvolvimento, ela ainda não agrega à situação conhecimentos prévios sobre outras coisas. Nas palavras de Vigotski:

Se observarmos uma criança de dois anos deixada ao seu livre arbítrio, veremos que sua atividade é infinita, que mexe constantemente (nos objetos); sua atividade, no entanto, está circunscrita a uma situação concreta, ou seja, faz somente aquilo que lhe sugerem os objetos circundantes (VYGOTSKI, 2012, p. 343, tradução e parêntese nosso).

A ação com objetos nascida no interior da atividade de comunicação emocional com o adulto desponta agora (por volta do segundo ano de vida) como atividade dominante, denominada atividade objetal manipulatória. Os objetos passam a apresentar-se como instrumentos com determinadas formas e usos, função designada pela experiência social. Neste segundo momento, a criança busca apropriar-se da função específica do objeto, reproduzindo as ações e operações que aprende com o adulto, pela via da imitação e do ensino (PASQUALINI, 2013).

O que marca a situação social de desenvolvimento deste período é a dependência das circunstâncias. Vigotski (2012) explica que as circunstâncias determinam a sua conduta como se fizessem parte dela. Assim, os objetos, conforme as situações em que se apresentam tem uma dada força afetiva para a criança que incita (ou não) e orienta sua ação. Consequentemente orienta do mesmo modo sua atenção, trazendo como resultado grande dependência da situação presente. Seu intelecto é prático, se precisa alcançar um objeto que não está próximo, por exemplo, é capaz de se valer de outros objetos que possam auxiliá-la a cumprir seu objetivo.

Aquilo que a criança percebe e incita sua ação é também aquilo que a afeta, desta forma, neste momento do desenvolvimento a percepção se encontra estreitamente vinculada aos matizes afetivos das coisas. Pode-se dizer, de acordo com Vygotski (2012), que a unidade percepção-ação-sentimento é o que caracteriza a consciência da criança na primeira etapa da primeira infância. A união entre percepção e ação não representa mais uma relação reflexa primária, mas uma relação movida pelo afeto. "Para a criança da primeira infância, a 
tomada de consciência não equivale a perceber e elaborar o percebido com a ajuda da atenção, da memória e do pensamento. Tais funções não estão diferenciadas, atuam na consciência subordinadas à percepção na medida em que participam do processo perceptivo" (VYGOTSKI, 2012, p. 344).

Ocorre que, concomitante a estes processos perceptivos que predominam neste período, uma nova aquisição está acontecendo no desenvolvimento da criança, trata-se da formação da linguagem oral. Pelo próprio processo de comunicação que permeia a relação dos adultos com a criança, aqueles impulsionam-na ao domínio da linguagem e este novo domínio leva a uma nova configuração da consciência. São os adultos que indicam o uso das palavras, apresentam o significado coletivo destas e, mediante essa interação, a criança passa a perceber que as palavras têm relação com as coisas da realidade. Portanto, a linguagem acompanha todas as transformações que ocorrem nesta etapa da vida, como o desenvolvimento do jogo de papéis, o desenvolvimento motor, a reorganização da memória, da atenção e da percepção, uma vez que a criança está em constante comunicação com as demais pessoas (VYGOTSKI, 2012).

Num primeiro momento a palavra e o gesto são inseparáveis na percepção infantil. É por volta da segunda metade do segundo ano de vida, que a referência objetal da palavra se "descola" do gesto indicador. Ela reage a uma determinada palavra pronunciada (objeto nomeado) sem que seja necessário fazer gestos ou indicações. Nesse caso, tem-se, de acordo com Luria (2001), a referência objetal independente, ou seja, é possível formar mentalmente a representação do objeto, requalificando os processos mnemônicos.

A aquisição da linguagem possibilita que ocorra uma espécie de duplicação do mundo para a criança que, aos poucos, pode ir se desvencilhando das representações imediatas. É o desenvolvimento das generalizações que torna possível a linguagem como um ato de comunicação, pois modifica-se o pensamento da criança, permitindo a ela reconhecer os objetos não apenas em sua relação situacional recíproca, mas em sua generalização verbal. Conforme assevera Vygotski (2012, p. 355), "Nas primeiras etapas, a generalização é possível somente quando a criança tem uma imagem visual-direta. A criança é incapaz de generalizar objetos ausentes, não pode falar do que não vê". Mais 
adiante, porém, ela passa a incluir os significados dos objetos em determinadas categorias, promovendo uma reorganização na sua forma de pensar (VIGOTSKI, 2009), uma vez que pode resgatá-los em sua memória.

Ocorre, com isto, o enriquecimento da capacidade de abstração, uma vez que, por meio da palavra, o número de vínculos e representações do objeto é maior que na simples percepção deste (VYGOTSKI, 2012). Este enriquecimento no pensamento da criança indica que ela está deixando o estágio sincrético e passando ao estágio do pensamento por complexos, que significa um momento qualitativamente superior no desenvolvimento da consciência. Neste momento, a generalização se dá pela construção de complexos de objetos particulares concretos, que são unidos mediante vínculos objetivos que realmente existem neles (VIGOTSKI, 2009). Sobre isso Martins (2013, p. 152) esclarece que:

“[...] a exposição repetida da relação entre palavra e objeto levará à expansão do campo perceptual e à consequente conexão entre a imagem sensorial captada e a palavra que a designa. Formam-se, assim, os conceitos mais primitivos, ou, na definição de Vigotski, os 'equivalentes funcionais dos conceitos' - traço que marca a gênese da unidade interfuncional entre atenção, linguagem e pensamento".

Com isso, podemos depreender que a atenção passa a orientar-se por mediações do pensamento por complexos, ou seja, pelas significações simples proporcionadas pela formação de $\operatorname{complexos}^{3}$. Porém ainda predomina na organização do psiquismo infantil a fusão entre estímulo e ação. Isto é, embora a criança opere com o significado das palavras sua ação ainda orienta-se a partir de fora, necessitando de direcionamentos por parte do adulto para organizar sua conduta e permanecer atento.

Concordamos com Pasqualini (2013) quando observa que na organização deste momento do desenvolvimento da criança não basta, pois, oferecer acesso à

\footnotetext{
3 Segundo estudo minucioso de Vygotski (2001) sobre o processo de formação de conceitos, em superação à fase anterior de sincretismo subjetivo e instável subjugado à percepção, o pensamento verbal por complexos permite generalizações que unificam objetos em grupos comuns, segundo características objetivas que de fato existem nestes. Trata-se de uma forma de pensamento coerente e mais estável, um verdadeiro salto em comparação ao pensamento sincrético, contudo suas generalizações ainda não são conceitos verdadeiros, pois se baseiam nos mais diversos fundamentos factuais e fortuitos das experiências espontâneas/cotidianas do sujeito.
} 
livre exploração, há que mediar o processo de apropriação, transmitindo os modos sociais de ação com os instrumentos culturais.

As conquistas possibilitadas pelo desenvolvimento da linguagem bem como pelo domínio das ações com os objetos, mediada pelos adultos, faz com que também as ações com os objetos se tornem generalizadas. Dessa forma, a criança aplica as mesmas ações a objetos diferentes, substituindo uns por outros num contexto lúdico. É pois no interior da atividade objetal manipulatória que começa a ser gestada uma nova atividade, o jogo simbólico, que irá promover o desenvolvimento ao longo do período pré-escolar.

O jogo simbólico tem origem no modelo de ação com os objetos que os adultos oferecem à criança. Ela aos poucos toma das ações dos adultos apenas o esquema mais geral que está relacionado com a significação social do objeto e, nas suas atividades lúdicas, passa a substituir uns objetos por outros. No início da ação lúdica, não é necessário que o objeto substitutivo tenha semelhanças com o original, o importante é a função que ele vai realizar (que é simbolicamente igual ao autêntico). O mais comum, na utilização dos objetos substitutivos no jogo, consiste em escolher aqueles sem forma e uso definido, como palitos, lascas, peças de quebra cabeça, os quais são inseridos no jogo como material complementar dos brinquedos temáticos (bonecas, carrinhos, animais de brinquedo), para atuarem como meio de execução de algum ato com os últimos (ELKONIN, 2009).

Nestas primeiras ações lúdicas, em que a criança atribui funções a outros objetos, abrem-se as possibilidades para que surjam os primeiros indícios de jogo protagonizado. A criança dá ao brinquedo principal (uma boneca, por exemplo) o nome de uma personagem, ou seja, uma identidade, destacando-o dos outros brinquedos como substitutivo da pessoa. Ela também começa a falar em nome do brinquedo que foi nomeado. Elkonin (2009) observa que, nestas manifestações, estão os indícios futuros da fala protagonizada, que não se articulam em nome do personagem interpretado pela criança, mas por intermédio da boneca.

O caminho de desenvolvimento do jogo, deste modo, vai da ação concreta com os objetos à ação lúdica sintetizada e, desta, à ação lúdica protagonizada. Elkonin (2009) exemplifica da seguinte forma: os adultos apresentam a colher à criança; em seguida, ensinam-lhe a sua funcionalidade: dar de comer com a colher; esta ação é transferida para uma ação lúdica: dar de comer com a colher à 
boneca e, então, a criança passar a representar o papel dar de comer à boneca como a mamãe, no qual fala como se fosse a mamãe. Todas estas transições, destaca o autor, requerem a direção dos adultos e cada uma delas, por sua vez, da mesma forma requerem modos especiais de direção. A ideia da espontaneidade do desenvolvimento do jogo protagonizado pelas crianças deriva do fato dos adultos muitas vezes não se aperceberem da direção que exercem realmente, uma vez que este processo costuma transcorrer de maneira assistemática e heterogênea no interior vida cotidiana.

O conteúdo do jogo se enriquece em decorrência das ideias que as crianças têm da realidade circundante, se não as têm, não se pode levar o jogo adiante. Daí a importância da participação do adulto no direcionamento das atividades dela. Ao adotar a postura de um personagem no jogo e ao assumir um papel determinado, a criança se vê forçada a destacar da realidade as ações e as relações dos adultos necessárias para cumprir a tarefa lúdica. Assim, ela até pode saber, antes do jogo começar, as diferenças existentes nas atividades de uma cozinheira e de uma professora, mas é só quando se coloca no lugar de uma delas que a criança se vê diante da necessidade de encontrar e destacar as relações e funções do papel que assumiu (ELKONIN, 2009).

Uma das conquistas essenciais proporcionadas pelo jogo protagonizado é o autodomínio da conduta. Isso se dá porque as ações da criança tornam-se objeto de sua consciência pela primeira vez e ela se esforça para controlá-las. Vygotski (2012) explica que uma criança que aprende a concordar e coordenar suas ações com as ações dos demais, isto é, que aprende a superar seu impulso imediato e subordinar sua atividade a uma ou outra regra lúdica atua, no início, como membro de uma coletividade única de todo o grupo de crianças que jogam. A subordinação às regras, a superação dos impulsos imediatos, a coordenação das ações pessoais e coletivas, no começo, da mesma forma que a discussão, constituem a primeira forma de comportamento entre as crianças que, mais tarde, transforma-se na forma individual da conduta do próprio sujeito.

Dito de outra forma, os conteúdos das atividades do jogo protagonizado na idade pré-escolar possibilitam que as novas aquisições se tornem conscientes, apoiando-se em mecanismos externos e internos, ou na dupla estimulação como propõe Vygotski (1995). A atenção, requerida para as atividades lúdicas configura 
elemento importante para a aquisição dos significados sociais inerentes a elas, contribuindo para a formação do pensamento por complexos que se desenvolve ao longo desta etapa. Se a atenção é a função psíquica responsável pela orientação da atividade a um fim consciente, então a própria subordinação da conduta às regras do jogo e às características dos papéis sociais na atividade, ao mesmo tempo, demanda e depende do avanço da atenção voluntária destes sujeitos para se realizar concretamente, mesmo que neste ponto ainda bastante dependente do controle externo dos adultos para se consumar como tal.

Ainda na idade pré-escolar a criança começa a ter um conjunto de obrigações elementares e seu vínculo com os adultos assume novas formas. Pela primeira vez torna-se possível um ensino sistemático e desenvolvido segundo um programa definido. Por meio da sua função simbólica, o jogo protagonizado contribui para que, em períodos posteriores, a criança adquira capacidades ainda mais amplas de simbolização, conquistando o domínio da escrita e da leitura. $\mathrm{O}$ jogo provoca mudanças qualitativas na estrutura psíquica e forma as bases necessárias para a atividade escolar (MARTINS; FACCI, 2016).

O período da idade escolar é marcado pela atividade da criança orientando-se para a assimilação de conhecimentos. O que marca a transição para a idade escolar é o movimento entre o desejo de "fazer o que o adulto faz" para "saber o que o adulto sabe"; este é o mote da atividade de estudo (PASQUALINI, 2013). A atividade de estudo é, portanto, orientada para um resultado. As premissas são formadas no período anterior - das atividades lúdicas vão surgindo as atividades produtivas (desenho, pintura, construção, primeiras tentativas de escrita etc.) linhas consideradas acessórias no desenvolvimento pré-escolar que serão centrais na idade escolar.

Nessa nova etapa, o entorno da criança organiza-se para a aquisição de conhecimentos, pais e professores dão grande ênfase à realização das tarefas em casa e a criança tem que mostrar bom desempenho. Por isso, no início da vida escolar a criança necessita de atividades que desenvolvam o interesse pelo estudo, tal interesse deve ocorrer na interação do aluno com o professor, no processo de transmissão e apropriação do conhecimento (MARTINS; FACCI, 2016). 
A interação professor-aluno provoca a necessidade de assimilação real dos conhecimentos teóricos destinados a realizar as atividades de estudo correspondentes. Para tal, é importante que o professor possa explicitar ao aluno a finalidade posta em cada tarefa, pois como afirmam Martins e Facci (2016), se as tarefas apresentadas às crianças carecem de sentido, o cumprimento das mesmas torna-se uma mera obrigação e isso corrobora para que o aluno a se distraia, uma vez que os motivos de fazê-lo devem ser os principais orientadores da atenção mediada.

Sobretudo nos primeiros anos da idade escolar os aspectos involuntários da atenção ainda são bastante evidentes, portanto, ainda há a necessidade de mediação externa para garantir a atenção da criança, isso porque o pensamento ainda não opera com os verdadeiros conceitos, de tal forma que os conteúdos em si não são suficientes para a manutenção da atenção. Assim, Petrovski (1980, p. 186) explica que nos anos iniciais:

O estado de atenção dos alunos se determina pelas particularidades da docência, depende tanto do conteúdo do material das lições como de sua exposição. A exposição clara, animada e emocional de um material com bastante conteúdo, mas ao mesmo tempo acessível e interessante, é o método mais importante de manipulação da atenção involuntária e condição para que os escolares estejam atentos à aula.

Os conteúdos curriculares apropriados pelo escolar proporcionam novos enlaces no pensamento que implicam na superação dos comportamentos elementares em direção aos comportamentos superiores uma vez que, conforme os conteúdos apresentam nexos entre si, a criança tem que tomar consciência dos conhecimentos que está adquirindo, formando os pré-conceitos (MARTINS; FACCI, 2016).

Com o processo de internalização de novos conteúdos e enriquecimento das operações internas do pensamento, a atenção torna-se cada vez mais mediada por tais conteúdos. No entanto, as conexões entre estímulos externos e internos ainda são incipientes, necessitando de recursos externos para manter-se atenta. Podemos pensar na própria fala do professor como exemplo de recurso externo 
que atua na formação de motivos internos da atenção da criança. Quando este chama atenção do escolar para um aspecto específico do conteúdo ensino, da ação a ser realizada, ou ainda, quando por meio dos exemplos que traz na aula faz enlaces conceituais com a criança, está a orientar externamente a atenção dela ao mesmo tempo em que retoma a explicação do conteúdo como signo mediador do ato voluntário que está em processo de internalização, de forma que internamente esta função também possa se reorganizar. Martins (2013, p. 153) sumariza este momento transitório de atenção voluntaria externa da seguinte forma:

[...] sob condições que promovam a internalização de signos, a atenção mediada revelará seus primeiros indícios, apontando conexões, ainda que incipientes, entre estímulos externos e operações internas; dando margem para que, nos anos subsequentes, os próprios meios externos sejam utilizados com maior adequação, enriquecendo a qualidade atencional como operação interna.

A respeito da importância da aquisição de conteúdos científicos proporcionados pela atividade de estudo, Sforni (2016) explica que tais conteúdos escolares são, essencialmente, mediadores culturais que permitem a formação e desenvolvimento do pensamento teórico. Isso significa que, enquanto ato de pensamento, um conceito vai além da mera denominação mais complexa para objetos e fenômenos do real, ele implica uma nova forma de percepção e organização do real, um modo de ação mental que permite tornar presente o que fisicamente está ausente. Para ilustrar, a autora cita como exemplo o conceito de felino. Ao chamarmos um gato de felino não estamos apenas lhe atribuindo um nome, mas ao mesmo tempo priorizando e preterindo certas características que permitem incluí-lo ou excluí-lo numa classe geral. Para que isso ocorra há um movimento de articulação entre as funções psíquicas, conforme explica a autora:

A atenção deliberada entre o particular (cada animal) e o geral (características essenciais) faz-se necessária; a percepção é dirigida aos aspectos relevantes; a memória passa a contar com elementos mediadores de caráter lógico, para identificar e reter características desse grupo de animais. O raciocínio conta com 
novas possibilidades de movimento entre o particular e o geral e vice-versa (SFORNI, 2016, p. 55).

Esse movimento do pensamento possibilita aos sujeitos que, por meio dos conhecimentos já adquiridos, seja possível conhecer novos objetos particulares mesmo sem a necessidade de contato físico com eles. Retomando o exemplo supracitado a respeito do conceito de felino, o sujeito ao internalizar tal conceito, mesmo não tendo contato com um leopardo, um leão, um tigre, ao saber que tratam-se de felinos, consegue antecipar seus hábitos, aparência, alimentação, procriação, etc. Caso fosse necessário interagir pela primeira vez com esse animal, ele já nos seria parcialmente conhecido, o que nos ofereceria condições de planejar e organizar ações conforme nossa intencionalidade, como fuga, caçada, domesticação (SFORNI, 2016).

Portanto o conceito interpõe-se entre o sujeito e o objeto favorecendo novas formas de pensamento e ação. $\mathrm{O}$ elemento novo que o domínio de conceitos possibilita ao sujeito não é a posse desarticulada de maior quantidade de conteúdos, mas essencialmente uma nova qualidade de pensamento que tem por signos mediados tais conteúdos e seus nexos dinâmico-causais. Esta nova qualidade é alcançada no período da adolescência devido ao acúmulo sintético de conhecimentos que a idade escolar proporcionou. A transição para este momento do desenvolvimento é marcada pelo surgimento de uma nova maneira de pensar que foi anteriormente engendrada pela atividade de estudo. Esta nova maneira de pensar é o pensamento por conceitos e a consequente estruturação da personalidade e da concepção de mundo (ANJOS; DUARTE, 2016).

Vigotski (2009) chama de pensamento conceitual a última fase do processo de formação de conceitos, posterior aos já mencionados complexos. Diferentemente destes, o pensamento conceitual se caracteriza pela superação da necessária conexão do conteúdo do pensar às experiências factuais, alcançando dimensões mais abstratas e essenciais dos fenômenos cognoscíveis, tornando suas generalizações superiormente universais e verdadeiras. Este autor é claro em afirmar que tal estado não se consolida antes da adolescência e dependerá de condições interpsíquicas adequadas para se formar de fato. Vigotski complementa sua argumentação esclarecendo que há inclusive diferenças significativas entre o 
grau de abstração dos próprios conceitos a serem internalizados, distinguindo-os entre espontâneos e científicos. Os primeiros são ligados às experiências cotidianas e seus alcances estão mais próximos da captação aparente do real; já os conceitos científicos, por serem resultado do estudo sistemático e comprometidos com a superação destas aparências, chegam a níveis abstrativos ainda mais amplos e precisos. Para o autor os conceitos espontâneos são normalmente a base sobre a qual ocorre o ensino dos científicos, superando-os. Por isso seriam acessíveis aos educandos apenas por meio do ensino sistemático; daí sua defesa clara de que a educação escolar tenha os conteúdos sistemáticocientíficos como foco.

A atenção passa então a ser subordinada ao pensamento por conceitos, o que significa que, o processo de internalização dos meios externos possibilitou que atenção se tornasse voluntária e internamente orientada, uma vez que "A etapa superior do desenvolvimento da conduta segue sendo complexa, mas prescinde de signos externos" (VYGOTSKI, 1996, p. 146).

A imagem subjetiva da realidade objetiva, portanto, só poderá alcançar sua maior fidedignidade a partir do pensamento conceitual. A realidade objetiva não é estática, por isso, somente por conceitos é que ela pode ser compreendida em sua totalidade, historicidade e movimento. Por meio dos conceitos é possível, então, a inteligibilidade do real e o desenvolvimento do psiquismo como um todo (MARTINS, 2013).

Conforme exposto, os processos cognitivos alcançados nesse momento do desenvolvimento permitem ao sujeito orientar sua atenção internamente de forma voluntária. A função em questão passa a ser eminentemente determinada pelo motivo da atividade e finalidades das ações, em que a pessoa cria os estímulos para orientar a própria atenção, intimamente vinculado ao pensamento conceitual abstrato. Por isso Martins (2013, p. 153) conclui: “[...] se ao princípio do processo a atenção conduz à formação dos conceitos, com o desenvolvimento da atenção arbitrária, superior, essa relação se inverte e, nela, os conceitos adquirem a capacidade de dirigi-la."

No entanto, cabe destacar que este processo não se dá de forma espontânea. Acontecerá somente se a etapa anterior, por meio da atividade de estudo que engendra o pensamento teórico, proporcionar as condições para tal. 
Além disso, Vigotski (1996) observa que no desenvolvimento do adolescente há uma contradição entre a nova forma de pensamento que está em desenvolvimento (pensamento por conceitos) e o fato de que este novo estágio do pensamento é ainda muito instável. O adolescente está aprendendo a pensar por conceitos, o que muitas vezes implica em certa unilateralidade no pensamento bem como na necessidade de retorno a apoios externos para organização da conduta do sujeito, logo também de sua atenção.

Esta transição do pensamento situacional para o pensamento taxonômico conceitual tem relação direta com a atividade em que o adolescente é inserido. A força motivadora que aciona o desenvolvimento e o amadurecimento do comportamento do adolescente está localizada nos problemas que o contexto coloca diante dele e que estão vinculados à sua projeção na vida cultural, profissional e social dos adultos. Vigotski (2009) salienta que, se o meio não apresenta novas exigências, não motiva e nem estimula o desenvolvimento do intelecto, este não alcançará todas as potencialidades que contém, não atingirá as formas superiores ou as alcançará com atrasos. Daí a possibilidade de compreendermos porque, diante de tantas intervinculações entre atenção voluntária, motivos das atividades e requalificação da compreensão do real pelo pensamento conceitual, o fenômeno da atenção de adolescentes seja tão complexo e esteja envolto de tantas queixas e imprecisões advindas juízos aparentes, sobretudo numa sociedade onde a alienação social facilmente esvazia de sentido a maior parte de todo que fazemos.

Considerando que a escola ainda ocupa espaço importante na vida do adolescente, destacamos a partir dos estudos de Anjos e Duarte (2016) que o professor deve programar os conteúdos de forma a ampliar o desenvolvimento do pensamento conceitual que se constitui neste estágio do desenvolvimento. A atividade docente deve ser intencional, direta e não espontânea, já que a formação dos conceitos científicos também tem relação direta com a qualidade da educação escolar e, como vimos, da atenção voluntária propriamente dita. O desenvolvimento dos conceitos científicos é fundamental para o desenvolvimento da autoconsciência, para o trabalho com abstrações mais elaboradas, para a formação de uma concepção de mundo que possibilite refletir sobre a realidade antes da busca de soluções imediatas. 


\section{Considerações finais}

Conforme exposto inicialmente, o objetivo deste texto foi apresentar a constituição da função psicológica atenção e as transformações ocorridas neste processo na medida em que mudam as atividades-guia que orientam o desenvolvimento. Sem desconsiderar os limites encontrados para abordar temática de tamanha complexidade, esperamos ter demonstrado até aqui que, para a Psicologia Histórico-Cultural, existem sim interdependências que se alternam entre atenção e pensamento no interior do processo de periodização do desenvolvimento. Para tal, é importante considerar a análise das características das atividades-guia de cada período em relação ao papel da atenção dentro destas mesmas atividades. Em termos dialéticos, esse entendimento dos processos funcionais em questão é relevante tanto para pesquisadores quanto para professores, famílias e demais interessados no fenômeno da atenção voluntária, pois colabora para uma compreensão dinâmica, contextual, totalizante e contraditória não apenas desta função em específico, mas do desenvolvimento ontogenético em sua totalidade.

Sendo a atividade humana um fenômeno objetivo-subjetivo de relação do sujeito com o outro, com o mundo e consigo mesmo, e, sendo a atenção voluntária ao mesmo tempo orientada majoritariamente pelos motivos destas atividades e promovida pelas demandas geradas no interior das mesmas, faz sentido articular e intencionalmente criar situações sociais de desenvolvimento a partir destas atividades-guia que impulsionem o desenvolvimento da atenção voluntária. Isso pode ser uma importante e viável alternativa para a superação de queixas (especialmente as escolares) relacionadas à falta de atenção e autocontrole da conduta.

\section{Referências}

ANJOS, R. E.; DUARTE, N. A adolescência inicial: comunicação íntima pessoal, atividade de estudo e formação de conceito. In: MARTINS, L. M.; ABRANTES, A. A.; FACCI, M. G. D. Periodização histórico-cultural do desenvolvimento psíquico: do nascimento à velhice. Campinas: Autores Associados, 2016. Cap. 9, p. $195-220$. 
CHEROGLU, S.; MAGALHÃES G. M. O primeiro ano de vida: vida uterina, transição pós-natal e atividade de comunicação emocional direta com o adulto. In: MARTINS, L. M.; ABRANTES, A. A.; FACCI, M. G. D. Periodização históricocultural do desenvolvimento psíquico: do nascimento à velhice. Campinas: Autores Associados, 2016. Cap. 4, p. 93-108.

ELKONIN, D. B. (2009). Psicologia do jogo (2 a ed. Álvaro Cabral, Trad.). São Paulo: WMF Martins Fontes (Obra original publicada em 1978).

LEONTIEV, A. N. (2004). O desenvolvimento do psiquismo. (2 ${ }^{\mathrm{a}}$ ed. Rubens Eduardo Frias, Trad.). São Paulo: Centauro

LURIA, A. R. (1979). Atenção e memória. In: LURIA, A. R. Curso de Psicologia Geral (Vol. III). Rio de Janeiro: Civilização Brasileira.

LURIA, A. R. (2001). Pensamento e linguagem: as últimas conferências de Luria. Porto Alegre: Artes Médicas.

MARTINS, J. C.; FACCI, M. G. D. A transição da educação infantil para o ensino fundamental: dos jogos de papéis sociais à atividade de estudo. In: MARTINS, L. M.; ABRANTES, A. A.; FACCI, M. G. D. Periodização histórico-cultural do desenvolvimento psíquico: do nascimento à velhice. Campinas, SP: Autores Associados, 2016. Cap. 7, p. 149-170.

MARTINS, L. M. Sobre o processo funcional atenção. In: _ . O desenvolvimento do psiquismo e a educação escolar: contribuições à luz da psicologia histórico-cultural e da pedagogia histórico-crítica. Campinas: Autores Associados, 2013. p. 141-154.

PASQUALINI, J. C. Periodização do desenvolvimento psíquico à luz da escola de Vigotski: a teoria Histórico-Cultural do desenvolvimento infantil e suas implicações pedagógicas. In: MARSIGLIA, A. C. G. (Org.). Infância e Pedagogia Histórico-Crítica. 1ed. Campinas: Autores Associados, 2013. Cap. 4, p. 71-97.

PETROVSKI, A. La atención. In: Editorial Progresso, 1980. p. 170-188.

Psicologia General. Moscou:

SFORNI, M. S. F. Ensino, aprendizagem e desenvolvimento: contribuições da teoria da atividade. In: OLIVEIRA, C. S. L.; CHAGAS-FERREIRA, J. F.; MIETO, G. S. M.; BERALTO, R. Psicologia dos processos de desenvolvimento humano: cultura e educação. Campinas, SP: Alinea, 2016. Cap.3, p. 53-66.

SILVA, J. C. É hora de trocar a fralda: contribuições da Teoria Histórico-Cultural para o trabalho com bebês na educação infantil. In: ARCE, A. (org.). Interações e brincadeiras na educação infantil. Alínea, Campinas-SP, 2013.

SMIRNOV, A. A.; GONOBOLIN, F. N. (1960). La atención. In: A. A. SMIRNOV; S. L. RUBINSTEIN; A. N. LEONTIEV; TIEPLOV, B. M. (Orgs.). Psicologia 
(Cap. VI, pp. 177-200, Florência Villa Landa, Trad.). México: Tratados y Manuales Grijalbo.

VIGOTSKI, L. S.; LURIA, A. R. (1996). A criança e seu comportamento In: VIGOTSKI, L. S.; LURIA, A. R. Estudos sobre a história do comportamento: símios, homem primitivo e criança (cap. 3, pp. 151-238). Porto Alegre: Artes Médicas.

VIGOTSKI, L. S. (2009). A construção do pensamento e da linguagem (2 ed. Paulo Bezerra, Trad.). São Paulo: WMF Martins Fontes (Obra originalmente publicada em 1934).

VYGOTSKI, L. S. (2012). Obras Escogidas (Tomo IV). Madrid: Antonio Machado. (Obra originalmente publicada em 1933).

VYGOTSKI, L. S. Desarrollo de las funciones psíquicas superiores em la edad de transición (item 4). In: Madrid: Visor, 1996. p. 137-151.

VYGOTSKI, L. S. Dominio de la atención. In: Obras escogidas. Problemas del desarrollo de la psique. Tomo III. Madrid: Visor, 1995. p. 213-245

VYGOTSKI, L. S. Obras escogidas. Incluye Pensamiento y lenguaje, Conferencias sobre psicología. Tomo II. Madrid: Visor, 2001. 